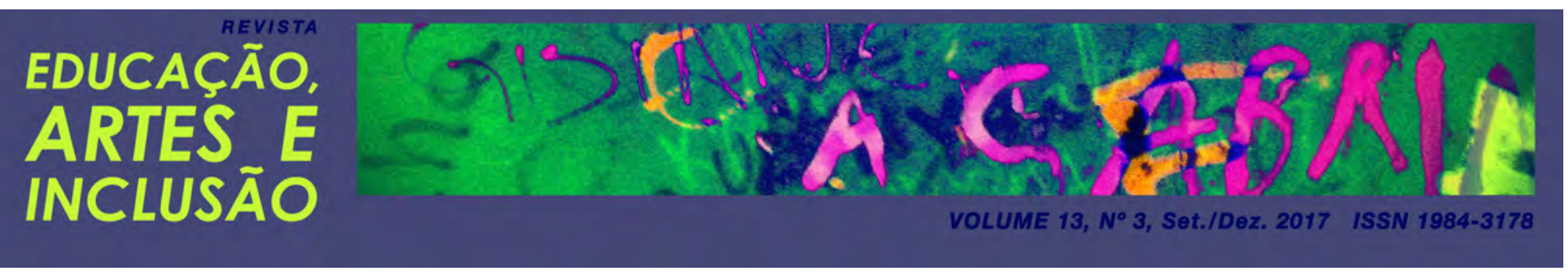

\title{
CIENCIARTE OU CIÊNCIA E ARTE? REFLETINDO SOBRE UMA CONEXÃO ESSENCIAL
}

\section{ARTSCIENCE OR SCIENCE AND ART? REFLECTING ON AN ESSENTIAL CONNECTION}

\author{
DOI: http://dx.doi.org/10.5965/1984317813032017158 \\ Anunciata Cristina Marins Braz Sawada, Tania Cremonini de Araújo-Jorge - Fundação Oswaldo Cruz, Francisco \\ Romão Ferreira - Universidade do Estado do Rio de Janeiro
}

\begin{abstract}
RESUMO:
A relação entre ciência e arte testemunha a reconciliação necessária ao nosso tempo, a fim de que ambas possam partilhar e contribuir com elementos essenciais ao ensino e ao desenvolvimento das sociedades. O ensino, a pesquisa, e o desenvolvimento de tecnologias sociais e educacionais sobre a relação entre Ciência e Arte na pós-graduação no Instituto Oswaldo Cruz/Fiocruz assumem o pressuposto de que a associação da arte à educação científica possibilitará aos educadores, e aos seus futuros alunos, desenvolver novas intuições e compreensões através da incorporação do processo artístico a outros processos investigativos, construindo um discurso interno e público sobre a relação entre arte, ciência, atividades humanas, e tópicos relacionados a atividades multidisciplinares e multiculturais. As atividades versam sobre temas variados em ciência, saúde e arte, e evidenciam a aplicação do novo paradigma ciênciarte na proposta. Expressam a apropriação do conteúdo debatido ao longo das pesquisas, promovendo o diálogo entre a ciência e a arte, reforçando o conceito "artscience", ou, em português, "arteciência" ou "cienciarte".
\end{abstract}

Palavras-Chave: Ciência. Arte. Criatividade. Ensino. Cienciarte.

\begin{abstract}
:
The relationship between science and art bears witness to the reconciliation necessary to our time, so that both can share and contribute essential elements to education and development of societies. Teaching, research and social and educational technology development of Science and Art in the Graduate Institute Oswaldo Cruz / Fiocruz take on the assumption that the association of art and science education will enable educators, and their future students, to develop new insights and understanding through incorporation of the artistic process to other investigative processes, building an internal and public discourse on the relationship between art, science, human activities, and topics related to multidisciplinary and multicultural activities. The activities deal with various topics in science, health and art, and demonstrate the application of the new paradigm of science \& art in the proposal. They express the ownership of the content discussed throughout the research, promoting dialogue between science and art, reinforcing the concept "ArtScience", or in Portuguese, "arteciência" or "ciênciarte".
\end{abstract}

Keywords: Science. Art. Creativity. Education. Artscience. 


\section{CIÊNCIA E ARTE: UMA HISTÓRIA DE MUITAS RELAÇÕES}

Uma das primeiras manifestações que remetem à relação entre arte e ciência pode ser vista no início da constituição do pensamento grego em Pitágoras. Os denominados pitagóricos captaram pela primeira vez as matemáticas e, além de desenvolvê-las, educados por elas, acreditaram que seus princípios eram os princípios de todas as coisas. A Escola Pitagórica defendia a purificação da mente através do estudo da Geometria, da Aritmética e da Música. Para os pitagóricos, por serem os números o fundamento da Matemática, eles apareciam em toda Natureza e eram os elementos de todas as coisas. Até os dias atuais músicos fazem uso da proporção áurea para o estudo da música. Segundo Bertrand Russel, os matemáticos modernos são herdeiros do pitagorismo, pois ele amplia a concepção numérica para a compreensão do mundo. Para ele,

[...] a noção de harmonia, no sentido do equilíbrio; o ajuste e a combinação de opostos, como o alto e o baixo, mediante uma afinação adequada; o conceito de caminho intermediário na ética, e a doutrina dos quatro temperamentos, tudo isso, afinal, remete à descoberta de Pitágoras (RUSSEL, 2003, p.36).

Matemática e música, portanto, nascem entrelaçadas e estão na base do pensamento ocidental. O gênio de Leonardo da Vinci (1452-1519), que atuou como pintor, escultor, engenheiro, anatomista, construtor e inventor, teve seu caminho pavimentado por Leon Batista Alberti (1404-1472), que se constituiu no primordial do "uomo universale", termo referente ao "homem renascentista" e que nos remete à ideia de alguém que transita por diferentes linguagens, saberes e habilidades. Segundo Bayer (1995), no tempo de Alberti, a ciência física ainda não existia, a busca da ordem e das proporções, das medidas certas, exatas, estavam a serviço da arte. Para Alberti, o belo é o perfeito, o bem distribuído, bem equilibrado. Aquilo a que nada se pode retirar ou acrescentar sem prejuízo. A arquitetura é pensada a partir de princípios racionais como: estabilidade, utilidade, equilíbrio entre as partes, ou seja, princípios matemáticos e geométricos. 


\section{EDUCACĀĀO,

Ao mesmo tempo Alberti atribui aos números virtudes ocultas, místicas, "sentenças pitagóricas", pois "o número governa a obra, assim como governa o mundo". O número possui finalidade, qualidade, função, posição no conjunto, distribuição e posição respectiva de todos os elementos. Em Alberti, a pintura é a ciência do traço, ela permite estabelecer uma relação entre a arte e a ciência (BAYER, 1995). Mas não foram somente Alberti e Leonardo a ligar as duas culturas, as duas formas de pensar em tempos mais antigos. Como exemplo temos Dürer, em suas ilustrações para um atlas de medicina, e Galileu (1564-1642) que, usando seus conhecimentos de perspectiva e geometria, seu domínio do desenho e da técnica renascentista do "chiaroscuro" (claro-escuro) que permitia a passagem da luz nos objetos, ressaltando assim seus volumes, permitiu ao cientista de Pisa desenhar uma Lua com seus relevos, inclusive determinando a altura de algumas montanhas lunares.

Ao contrário, seu contemporâneo inglês Thomas Harriot (1560-1621), dispunha de uma luneta semelhante em 1609, mas que não tinha o mesmo treinamento artístico do italiano. Por isso Galileu foi capaz de desenhar com perfeição enquanto seu rival pode esboçar somente manchas, sem nitidez (REIS et al., 2006). Michelangelo foi outro que, em parte de suas obras, nos transmitiu grande conhecimento da anatomia humana e de como esse conhecimento serviu de base para um detalhamento enriquecedor de músculos e ossos. Para Jimenez, no Renascimento, a ordem das coisas, o cosmos, era redutível a leis aritméticas e geométricas.

O número, portanto, era soberano, era sabedoria, harmonia e beleza. "Os artistas da Renascença aprendem as lições de Pitágoras, cujo nome aparece com frequência nos documentos de época; sentem eles um idêntico fascínio por essa cosmologia do número" (JIMENEZ, 1999. p.46). Para Leonardo da Vinci (1452-1519), “a arte é inseparável da ciência e não é mais do que a aplicação dela. Estamos, pois em plena mecânica e em pleno racionalismo" (BAYER, 1995, p.117).

Em tempos anteriores, a primeira parte do ensino universitário era formada pelas três disciplinas do Trivium (gramática latina, lógica e retórica), com disciplinas elementares que lidavam com a linguagem, seguidas pelas disciplinas do Quadrivium (aritmética, geometria, música e astronomia), que lidavam com os números. O trivium, basicamente, tinha a função de reorganizar a mente e, desta forma, preparar o caminho para o quadrivium. Juntas, elas 
constituíam as sete artes ou as artes liberais (Burke, 2003). Nesse período, o horizonte científico e o horizonte artístico se confundiam e não havia hierarquia entre esses saberes. Essa separação ocorrerá após a revolução científica moderna com o surgimento do método científico que, baseado na lógica, na matemática e nos princípios da razão, exclui tudo o que é sensível, subjetivo e emotivo. Essa divisão possibilitou a criação de "disciplinas" curriculares diferentes, coisa que não havia no período medieval. Para Peter Burke (2003), no mundo clássico a "disciplina" está ligada ao atletismo, com o exército e com a filosofia dos estoicos que enfatizavam o autocontrole. No período medieval a disciplina estava ligada aos mosteiros e à penitência, já no Século XVI os calvinistas falavam da disciplina da Igreja.

As disciplinas científicas em particular foram consideradas como uma "invenção" de fins do Século XVIII e início do XIX. Segundo ele, "o que era novidade por volta de 1800 não era tanto a ideia de uma disciplina, mas sua institucionalização na forma de "departamentos" acadêmicos (termo usado pela primeira vez em inglês em 1832, segundo o Oxford English Dictionary) (BURKE, 2003, p.86).

A partir da revolução científica moderna ocorrida nos Séculos XVI e XVII, a Ciência se consolidou como uma forma de produção de conhecimento baseada nos princípios da razão, da lógica e do pensamento matemático, visando uma interferência ativa e objetiva na natureza. A Ciência estava ligada à Filosofia, mas ao se desatrelar desta, passa a ter um conhecimento mais estruturado e prático. As causas principais dessa revolução podem ser resumidas em: renascimento cultural, imprensa, reforma protestante e hermetismo. A expressão "revolução científica", enquanto terminologia, foi criada por Alexandre Koyré, em 1939. Neste mesmo período, as preocupações teóricas do campo da Arte vão incorporar a subjetividade, a discussão acerca da moralidade, da sensibilidade, da cultura como uma segunda natureza, e da faculdade individual de julgamento do gosto. Ferreira (2010) ressalta que a Arte, subjetiva, se distanciou da objetiva Ciência, pois as características, a sensação, a imaginação, o sentimento, o entusiasmo, o gosto pessoal, as paixões, a memória, são critérios que se afastam do ideal de clareza, objetividade e verdade que constituem os pilares do pensamento científico. Esse afastamento da subjetividade, nas ciências em geral, e nas ciências da saúde em particular, pode se transformar num fator de limitação para a construção de um novo conhecimento e para a construção de novas alternativas de trabalho. Segundo Morin, 
A supremacia do conhecimento fragmentado de acordo com as disciplinas impede frequentemente de operar o vínculo entre as partes e a totalidade, e deve ser substituída por um modo de conhecimento capaz de apreender os objetos em seu contexto, sua complexidade, seu conjunto. (MORIN, 2000, p.14).

\section{UMA REAPROXIMAÇÃO DE CIÊNCIA E ARTE NO SÉCULO XXI?}

No domínio relativo à aproximação da Ciência e da Arte no processo educativo, alguns pesquisadores têm assumido posição de protagonismo nas pesquisas, tais como Todd Siler, que se tornou o primeiro artista visual a conseguir o $\mathrm{PhD}$ no Massachusets Institute of Technology, na área de Estudos Interdisciplinares em Psicologia e Arte em 1986. Siler é um artista americano multimídia, autor, educador e inventor, conhecido por sua arte e por seu trabalho em pesquisa em criatividade. Defende a integração das artes e das ciências e juntamente com Root-Bernstein, é um dos criadores do Movimento ArtScience, sobre o qual trataremos mais adiante, como um ponto essencial do processo de construção do campo arteciência. O casal Robert e Michelle Root-Bernstein (2001) sistematizou treze categorias cognitivas promotoras da criatividade: observar, evocar imagens, abstrair, reconhecer padrões, formar padrões, estabelecer analogias, pensar com o corpo, ter empatia, pensar de modo dimensional, criar modelos, brincar, transformar e sintetizar.

As categorizações descritas por Root-Bernstein e Root-Bernstein (2001) permeiam a construção do processo criativo em várias etapas. Através delas, usando exemplos de destacadas personalidades nos dois campos abordados, os autores mostraram que o pensar criativo na Ciência e na Arte pode ter vários pontos em comum.

Caracterizar as pessoas de acordo com as diferentes coisas que elas fazem é ignorar a universalidade de sua forma de criar. Pois, no plano do processo criador, cientistas, artistas, matemáticos, compositores, escritores e escultores usam um conjunto comum do que chamamos de "ferramentas para pensar", que incluem sentimentos, visualização de imagens, sensações corporais, padrões que podem ser reproduzidos, e analogias. E todos os pensadores de imaginação aprendem a traduzir as ideias geradas com essas ferramentas subjetivas do raciocínio em linguagens comuns para expressar seus insights, que depois podem levar ao surgimento de novas ideias na cabeça de outras pessoas (ROOT-BERNSTEIN E ROOT-BERNSTEIN, 2001, p.22). 
Tentando investigar as estruturas mentais em busca das respostas que nos levem a entender as sinapses cerebrais, Root-Bernstein e Root-Bernstein (2001) nos colocam que, até o momento, não existem respostas completas e uma das formas mais interessantes de realizar este estudo é através da análise dos depoimentos dos pensadores e artistas e de como se deu a formação de seus processos criadores. Um dos exemplos citados é o de Albert Einstein, cujo pensamento, poderíamos supor, basear-se-ia sempre num raciocínio matemático, quando ele mesmo tinha dificuldades com este campo, necessitando algumas vezes de auxílio, nesta área, em seus trabalhos. Na verdade, ele confessava que seus "elementos de pensamento" estariam traduzidos em signos e imagens, sendo alguns elementos "musculares". Ao lado do raciocínio de Einstein de que "nenhum cientista pensa com fórmulas", o autor coloca que embora seja possível trabalhar com um vislumbre intuitivo há necessidade de ser colocar de forma compreensível aos outros, trabalhando com métodos científicos capazes de validar esses pensamentos (ROOT-BERNSTEIN e ROOT-BERNSTEIN, 2001).

Tanto a ciência quanto a arte têm uma percepção da chamada "essência das coisas", cabendo ao cientista e ao artista a incumbência de desvendá-las, de reinterpretá-las de forma a tornar possível sua compreensão, por aqueles que não pertencem a nenhuma das "duas culturas", a científica e a humanística. Nesse diálogo podemos incluir também a Filosofia e sua capacidade de problematizar, desvendar e nomear novos modos de entendimento da realidade a partir de seus conceitos. Segundo Deleuze (1992), as Artes, a Filosofia e as Ciências são instâncias criadoras, são as três asas do conhecimento que utilizam a intuição, a imaginação, a criatividade, a razão, mas a criação de conceitos é competência da Filosofia. A Arte e a Ciência podem pensar por conta própria, elas não precisam da criação de conceitos. Elas produzem conhecimento a partir de outros canais, outros processos. A filosofia produz conceitos (conceptos), a Ciência produz proposições (prospectos) e a Arte produz percepções e sensações (perceptos e afectos). Segundo Deleuze,

os três pensamentos se cruzam, se entrelaçam, mas sem síntese nem identificação. A filosofia faz surgir acontecimentos com os seus conceitos, a arte ergue monumentos com suas sensações, a ciência constrói estados de coisas com suas funções. Um rico tecido de correspondências pode estabelecer-se entre os planos. (DELEUZE, 1992, p.254).

Mas não existe hierarquia entre essas três formas de pensamento, são instâncias produtoras de conhecimento que operam cada uma da sua forma, o que não nos impede de 
conhecê-las e colocá-las para dialogar. É possível ao indivíduo o "fazer ciência" ao mesmo tempo em que "faz arte". Em "As Duas Culturas", Charles Percy Snow nos falou de que forma a ciência pode ser útil à arte: "Ela deve ser assimilada juntamente com o conjunto de nossa experiência mental, e como parte integrante dela, e ser utilizada tão naturalmente quanto o resto" (SNOW, 1959, p.35). Em sua principal obra, Snow descreve a divisão das duas culturas, a científica e a humanística, mostrando as diversidades entre elas. Escrita em 1959, a obra apresenta uma contemporaneidade quando compara o nível de industrialização dos países observando a premente necessidade dos mais ricos ajudarem aos mais pobres para minimizar situações discrepantes e desiguais. Para Snow (1959), a quebra de comunicação entre as ciências e as humanidades e a falta de interdisciplinaridade, já notada em meados do século XX, era uma das principais dificuldades na resolução de problemas mundiais. O ser humano produziu conhecimento desde antes do que conhecemos como categorias formais de arte ou ciência. Para realizar a pintura rupestre ele precisou de instrumentos que o auxiliassem, para esculpir a Vênus de Willendorf há 25.000 anos atrás ele precisou também de uma capacidade criativa, de uma percepção abstrata e simbólica das coisas, uma linguagem mítica e uma cosmologia que explicasse o mundo. Esse ser humano, portanto, faz arte e ciência simultaneamente, sem fazer distinção entre elas. A proposta é transitarmos entre os dois modos de perceber e elaborar conhecimentos de si e do mundo, a partir dessas duas poderosas linguagens, Ciência e Arte.

A chamada ciência, tal como a descrevemos, brilhou inicialmente há cerca
de 10.000 anos ou mais, no Oriente médio. Teve início quando o homem
começou a reunir conhecimentos para a sua vida diária. Coligiam-se
particularidades de plantas, mesmo das que não tinham uso medicinal ou
alimentício; catalogavam-se animais, tanto os domésticos quanto os
selvagens, meios para levantar grandes pesos, desenvolvimento de técnicas
agrícolas, invenção da tecelagem, criação da cerâmica e fundição de alguns
materiais... (RONAN, 1987, p.16).

O conhecimento, portanto, é uma construção social que envolve as diferentes culturas (arte e ciência), o saber especulativo da filosofia, visões de mundo muitas vezes divergentes, interesses e conflitos de classe, relações de poder, crença, diferentes formas de coleta de informação e inúmeros interesses políticos, econômicos, militares, posições ideológicas, epistêmicas, envolvendo também o contexto social, momento histórico e os conflitos acadêmicos e institucionais. As divergências entre saberes disciplinares e propostas inter ou 
transdisciplinares fazem parte desse cenário. Pensar a produção de um conhecimento que articula arte e ciência significa navegar por este mar de incertezas. Mas navegar é preciso...

A proposição da intercessão entre Ciência e Arte encontra grande pertinência e mesmo validação enquanto um campo promissor de pesquisa e ensino no auxílio à formação e ao desenvolvimento de educadores e suas práticas em sala de aula. Essa visão será corroborada mais tarde por Morin (2000), como já vimos em citação anterior.

A mudança em nosso ponto de vista científico, de um ponto de vista separado para um holístico, tem impacto na educação.... Na educação convencional, há uma tendência de existir campos de estudo separados dentro de um currículo, sem conexão aparente entre eles... A educação consciente, em paralelo com o novo ponto de vista científico, assume uma integridade: tudo está conectado com todo o resto. Este "novo" princípio abre as portas para uma educação baseada em uma perspectiva holística um ambiente de aprendizado em que tudo é relevante para tudo, e cada aprendiz tem um papel importante. É criada uma oportunidade para mudar de uma educação baseada em informação para uma educação baseada no aprendiz. (KLUCHNIKOV, 1992, p. 8).

Para Root-Bernstein e Root-Bernstein (2001), tanto o cientista, como o artista realizam e descobrem padrões, sendo que esses padrões devem ser belos, pois não há lugar para uma ciência feia ou sem inspiração. Essa reflexão nos remete a outro poema de Fernando Pessoa, na pessoa de Álvaro de Campos (1928), mostrando que existe beleza nos dois saberes, pois ambos expressam a linguagem do conhecimento do mundo:

O Binômio de Newton é tão belo como a Vênus de Milo.

O que há é pouca gente para dar por isso.

óóóó---óóóóóó óóó---óóóóóóó óóóóóóóó (O vento lá fora.)

(PESSOA, 2013, p.526).

Recolhendo, estudando e interpretando as histórias contadas por pensadores, artistas, cientistas e inventores eminentes, Root-Bernstein e Root-Bernstein (2001) concluíram que através da arte os cientistas encontram as ferramentas para tornar explícita a beleza da produção de conhecimento, seja na arte ou na ciência. Esse é um referencial básico que 
justifica o esforço para introduzir formalmente Ciência e Arte na programação curricular de uma instituição educativa (escolas, centros de ciência, centros de arte, museus).

A utilização das duas linguagens, dos dois campos de pensamento, Ciência e Arte, adquire um caminho de validação na estratégia pedagógica para todos os níveis de ensino, desde o ensino fundamental em toda e qualquer escola, até o ensino de pós-graduação, para a formação de docentes e cientistas numa formação holística (ARAUJO-JORGE, 2004). A arte pode se combinar com a ciência como parte de uma estratégia pedagógica explícita para a educação científica da população, e, para a educação e a divulgação científicas, a arte precisa ser incluída como nos ensina Frank Oppenheimer:

...não apenas para tornar as coisas mais belas (...) os artistas fazem descobertas sobre a natureza diferentes daquelas que fazem os cientistas e também usam bases diferentes para tomar decisões enquanto criam suas obras - seus experimentos. Mas, tanto artistas como cientistas nos ajudam a notar e a apreciar as coisas da natureza que aprendemos a ignorar, ou que nunca nos ensinaram a ver. Tanto a arte como a ciência é necessária para o completo entendimento da natureza e de seus efeitos nas pessoas. (OPPENHEIMER apud ARAÚJO- JORGE, 2004, p.23).

Ao nos balizarmos nos investigadores do campo da Ciência e da Arte, identificamos a importância e a relevância deste assunto no aprofundamento da construção de paradigmas em Pesquisa e Ensino. A percepção do uso complementar dos conceitos e proposições descritas nas teorias de arte e de ciência pode acrescentar de maneira essencial, um novo aspecto e uma nova abordagem na tentativa de dinamizar e enriquecer esta nova área de pesquisa, bem como trazer novas abordagens ao panorama educacional. Cristina Costa em seu livro "Questões de Arte: o belo, a percepção estética e o fazer artístico", nos ajuda a perceber pontos comuns entre os saberes quando diz que despertar a intuição artística, desenvolver suas formas de expressão e ampliar a capacidade de absorvê-la está relacionado intimamente com o despertar de nossa humanidade (COSTA, 2004). Se pensarmos que também a Ciência está ligada a todas estas características, concluiremos que está diretamente relacionada ao ser humano de forma a preservar e manter sua humanidade. Conjugando-se com sua história e conquistas, notamos o quanto a Ciência e a Arte têm em comum e o quanto elas podem influenciar num novo olhar, ao sensibilizar aquele cujo foco poderá estar circunscrito a seu interesse profissional, sem atentar para a importância da conjunção de modos de pensar diferenciados. 


\section{CIÊNCIA E ARTE: A CONSTRUÇÃO DE UM CAMPO NO BRASIL E NO EXTERIOR}

O campo da pesquisa envolvendo Ciência e Arte vem ganhando espaço nos últimos anos no Brasil e no exterior. São cada vez mais frequentes exposições de arte e ciência, como as organizadas pelo Projeto Portinari em diversas cidades do país, simpósios e palestras sobre arte e ciência, como os organizados, por exemplo, pelo Instituto Oswaldo Cruz, Museu da Vida e Casa da Ciência da UFRJ. Universidades e centros de pesquisa começam a introduzir ciência e arte em programas de estágio (ex. Unicamp: Programa ciência e arte nas férias, 2003,2004), cursos (ex: Inst. Oswaldo Cruz: cursos de Ciência e Arte) e disciplinas de graduação (ex: Medicina de família: ciência e arte como metodologia acadêmica - Prof. Pablo González Blasco). Em outros países, podemos citar o Exploratorium em São Francisco, o Laboratório de mídia do MIT, Le Laboratoire em Paris, SymbioticA em Perth e a Iniciativa para Computação Inovativa da Universidade de Harvard. Todos têm em seus organogramas departamentos específicos de ArtScience, termo que vem substituindo e criando um novo pensar na área. $\mathrm{Na}$ busca por outras experiências similares de cursos e disciplinas que articulem ciência e arte no Brasil e no exterior, a internet tem sido uma importante fonte de informação. Destaca-se que no âmbito do governo federal brasileiro, as instâncias ministeriais da Educação e Cultura e da Ciência e Tecnologia, desenvolveram algum apoio às propostas de criação de Oficinas de Arte e Ciência nos municípios e nas escolas brasileiras, como apontou a Folha de São Paulo em 29/7/2003. O IV Congresso Internacional de Centros e Museus de Ciência, realizado em abril de 2005 no Rio de Janeiro sob a coordenação geral da Fiocruz Museu da Vida teve como um dos eixos centrais justamente Ciência e Arte. Registra-se ainda que nas reuniões anuais e regionais da SBPC a inclusão de atividades de arte e ciência em sua programação tem atraído cientistas, artistas e professores para este debate. E os Simpósios de Ciência, Arte e Cidadania organizados bianualmente pelo Instituto Oswaldo Cruz com diversos parceiros, chegou à sua $9^{\mathrm{a}}$ edição em 2015, numa organização conjunta pela primeira vez com um Museu de Arte, o MAR, Museu de Arte do Rio. Esse simpósio, em particular, 
por ter sido todo registrado em vídeo e estar integralmente disponível gratuitamente na internet ${ }^{1}$, é um marco importante do avanço desses movimentos.

Araújo-Jorge e colaboradores (2006) nos informam que a ciência e a tecnologia fazem parte do dia a dia e a temática científica encontra-se presente em vários assuntos do cotidiano, tais como vacinas, clonagem genética, novas terapias, etc. Acrescenta ainda que muitas decisões políticas estão diretamente relacionadas aos conhecimentos científicos diferenciados daqueles do senso comum (ARAÚJO-JORGE et al., 2006). Jeffrey Sachs (apud ARAUJO JORGE et al., 2006), da Universidade de Harvard, em seus estudos sobre a pobreza afirma que ciência e tecnologia são hoje mais excludentes que o capital, pois na sociedade da informação a dificuldade de acesso à escolaridade e à formação profissional produz mais pobreza e acentua as desigualdades sociais, perpetuando o ciclo de pobreza aos descendentes da família.

Acentua-se que no estágio atual da ciência, a criatividade e a capacidade de produzir novas tecnologias é a moeda principal e os países mais desenvolvidos são os que produzem patentes, desenvolvem novas tecnologias e oferecem produtos mais sofisticados ao mercado.

... a ciência não se desenvolve de modo autônomo no plano intelectual das ideias. Seus conceitos têm uma profunda relação com contexto histórico, tanto nos aspectos intelectual e cultural como nos aspectos econômico, social e político. Esta relação se dá em mão dupla... A ciência é influenciada pelo contexto social em que nasce e se desenvolve de onde se nutre pelos meios materiais e institucionais de que necessita e com a motivação intelectual e ética dos cientistas. (ROSA, 2005, p. 16).

É contrastante o desenvolvimento da pesquisa científica brasileira com o aproveitamento dos jovens nas escolas, nas áreas relativas à ciência: a maioria deles tem desempenho sofrível, estando abaixo da média de seus correspondentes em outros países. A capacidade de compreensão da língua portuguesa, de noções básicas de física ou da biologia,

\footnotetext{
${ }^{1}$ Ciência, Arte e Cidadania 2015 - 9o Simpósio https://www.youtube.com/watch?v=RnepdQHdQLQ\&t=289s parte 1 https://www.youtube.com/watch?v=mkoXfvan0g8\&t=253s parte 2 https://www.youtube.com/watch?v=c0PJ8HsylkE\&t=36s parte 3 https://www.youtube.com/watch?v=zDexpkPDxjw $\& \mathrm{t}=15 \mathrm{~s}$ parte 4 https://www.youtube.com/watch?v=zDexpkPDxjw $\& \mathrm{t}=15 \mathrm{~s}$ parte 5 https://www.youtube.com/watch?v=zDexpkPDxjw\&t=15s parte 6 https://www.youtube.com/watch?v=Ly9meC8zac4\&t=34s programação cultural
} 
ou compreensão do processo histórico, são falhas que o nosso ensino básico insiste em perpetuar. Portanto, não é possível tornar o país competitivo no mercado mundial com esse déficit educacional. Temas como esses foram objeto de discussão na $3^{\text {a }}$ Conferência Nacional de Ciência Tecnologia e Inovação em 2005, e estão disponibilizados nos dados da conferência. O cenário nos mostra que a formação de professores de ciência passa por um estágio de enorme deficiência no que diz respeito a sua qualidade, para que sejam capazes de desenvolver nos estudantes um espírito questionador e crítico, não só nesta área como também na solução de dificuldades em seus mais diversos problemas. Isso permite ao governo brasileiro delinear um quadro que demonstra a necessidade de políticas e movimentos que envolvam a educação e a divulgação científica e que vem sendo implementadas no país, envolvendo cientistas, educadores e agências de fomento. É interessante notar que o artista pode sintetizar questões cruciais na discussão sobre a ciência, como exemplificado na música.

“A ciência em si” de Arnaldo Antunes e Gilberto Gil no disco Quanta, em 1995, demonstrando que a arte pode sensibilizar a percepção, via expansão de nossos sentidos, de nossos olhares, e nos facilitar o encontro de novas ideias e soluções:

Se toda coincidência/ Tende a que se entenda/ E toda lenda quer chegar aqui /

A ciência não se aprende / A ciência apreende / A ciência em si

Se toda estrela cadente / Cai pra fazer sentido/ E todo mito quer ter carne aqui

A ciência não se ensina / A ciência insemina / A ciência em si

Se o que se pode ver, / ouvir, pegar, medir, pesar / Do avião a jato ao jaboti

Desperta o que ainda não, não se pôde pensar / Do sono eterno ao eterno devir

Como a órbita da terra / abraça o vácuo devagar / Para alcançar o que já estava aqui

Se a crença quer se materializar/ Tanto quanto a experiência quer se abstrair

A ciência não avança / A ciência alcança / A ciência em si

(A CIÊNCIA EM SI, Gilberto Gil \& Arnaldo Antunes, 1995, Álbum Quanta) ${ }^{2}$

\footnotetext{
${ }^{2}$ Visto em: http://www.arnaldoantunes.com.br/new/sec_discografia_sel.php?id=94
} 
Esse é um referencial básico que vem em socorro da fundamentação necessária à presença de Ciência e Arte na programação curricular de uma instituição científica que forma cientistas e educadores, reinserindo a ciência como elemento da cultura. Através do estudo da imaginação criativa, encontramos a possibilidade de exercitá-la, treiná-la e educá-la. RootBernstein (2011) elaborou um documento, que foi publicado em forma de editorial na revista "Leonardo", intitulado "ArtScience: colaboração integradora para criar um futuro sustentável". Este documento se refere à proposição de uma terminologia com o foco mais abrangente intitulada ArtScience. Para ele,

ArtScience integra todo o conhecimento humano através dos processos de invenção e exploração. São, ambos, o novo e o velho, o conservador e o revolucionário, o lúdico e o sério...ArtScience moverá a arte para fora de galerias e museus, e a ciência para fora de seus laboratórios e periódicos, para espaços recém inventados..., que já fazem exploração científica, engenharia, design e exposição artística em um espaço único.... Nesta inventividade encontra-se a excitação de ArtScience. (ROOT-BERNSTEIN, 2011, p. 192).

Neste mesmo texto, Root-Bernstein e mais três pesquisadores lançaram o Manifesto ArtScience (ROOT-BERNSTEIN et al. 2011), com dezessete pontos, contendo proposições acerca dos objetivos: reintegrar o conhecimento e reumanizar este conhecimento, cultivando um novo Renascimento.

Temos trabalhado com esse texto, cuja tradução apresentamos aqui para disseminação em português do conceito CienciArte:

\section{O MANIFESTO CIENCIARTE}

1. Tudo pode ser compreendido através da arte, mas esse entendimento é incompleto.

2. Tudo pode ser compreendido através da ciência, mas esse entendimento é incompleto.

3. Cienciarte nos permite alcançar uma compreensão mais completa e universal das coisas.

4. Cienciarte envolve a compreensão da experiência humana da natureza pela síntese dos modos artístico e científico de investigação e expressão. 
5. Cienciarte funde a compreensão pessoal, subjetiva, sensorial, emocional, e pessoal com a compreensão pública, objetiva, analítica e racional.

6. Cienciarte não está embutida em seus produtos, ela incorpora a convergência de processos e habilidades artística e científica, e não a convergência de seus produtos.

7. Cienciarte não é Arte + Ciência ou Arte-e-Ciência ou Arte/Ciência, nos quais os componentes mantêm suas distinções e compartimentalização disciplinares.

8. Cienciarte transcende e integra todas as disciplinas ou formas de conhecimento.

9. Aquele que pratica Cienciarte é simultaneamente um Artista e um Cientista; é uma pessoa que produz coisas que são tanto artísticas quanto científicas simultaneamente.

10. Todo grande avanço artístico, impacto tecnológico, descoberta científica e inovação médica, desde o início da civilização, resultou de um processo de Cienciarte.

11. Todo grande inventor e inovador na história, foi um praticante de Cienciarte.

12. Deve-se ensinar Arte, Ciência, Tecnologia, Engenharia e Matemática como disciplinas integradas, não separadamente.

13. Devemos criar currículos baseados na história, na filosofia e na prática de Arteciência, usando as melhores práticas da aprendizagem experimental.

14. A visão de Cienciarte é a re-humanização de todo o conhecimento.

15. A missão de Cienciarte é a re-integração de todo o conhecimento.

16. O objetivo de Cienciarte é cultivar o Novo Renascimento.

17. O objetivo de Cienciarte é inspirar a abertura das mentes, a curiosidade, a criatividade, a imaginação, o pensamento crítico e a resolução de problemas através de inovação e colaboração!

(ROOT-BERNSTEIN, SILER, BROWN, SNELSON, 2011, p 192)

É preciso, portanto, resgatar a concepção de totalidade do "homem renascentista" formando alunos (artistas e/ou cientistas) que transitem por diferentes linguagens, saberes e habilidades.

Entre as ideias principais sugeridas pelo Manifesto Cienciarte podemos destacar 3 grandes blocos: os pontos 1 a 4 , pois que agregam o escopo desse campo 
ciênciarte/arteciência; os pontos 5 a 11, que qualificam o profissional artecientista, ou cienciartista, com seus tipos de compreensão e percepção, o seu processo de trabalho, que se diferencia de seu produto, e a convergência das habilidades desse profissional; e os pontos 12 a 17, que sintetizam a proposta cienciarte no ensino, trazendo seu potencial integrador e interdisciplinar, com uma visão, uma missão e um objetivo: "cultivar o Novo Renascimento", "inspirar a abertura das mentes, a curiosidade, a criatividade, a imaginação, o pensamento crítico e a resolução de problemas através de inovação e colaboração". Inovação surge, portanto, como um enorme benefício do processo de ensino através da desse novo campo cienciarte.

As atividades integradoras de Ciência e Arte assumem o pressuposto de que a associação da arte à educação científica possibilitará aos educadores, e aos seus futuros alunos, desenvolver novas intuições e compreensões através da incorporação do processo artístico a outros processos investigativos, bem como construir um discurso interno e público sobre a relação entre arte, ciência, atividades humanas, e tópicos relacionados a atividades multidisciplinares e multiculturais.

Leopoldo de Meis (1998) caracterizou esse processo como de dualidade "tecnologia versus humanismo", e constatou que ela é percebida também pelos jovens, influenciando provavelmente no momento de escolha de sua carreira. Em seu livro "Ciência e Educação: o conflito humano-tecnológico", publicado em 1998, de Meis aprofundou a reflexão sobre a dicotomia entre ciência e arte, e sobre a noção de que pertencem a campos antagônicos permeia a cultura das sociedades contemporâneas ocidentais. Citou o inglês C.P. Snow e o escritor americano John Burroughs para concluir que não há consenso sobre as semelhanças ou diferenças entre ciência e arte, mesmo entre os autores que se destacaram por suas contribuições nestes dois campos. Para Einstein, ciência e arte pertenceriam ao mesmo domínio, mas se expressariam com linguagens distintas:

Onde o mundo cessa de ser a cena de nossas esperanças e desejos pessoais, onde podemos encará-lo como seres livres admirando, perguntando, observando, aí entramos nos domínios da arte e da ciência. Se o que é visto e experimentado é mostrado com a linguagem da lógica, estamos engajados em ciência. Se é comunicado através de formas cujas conexões não são acessíveis à mente consciente, mas são reconhecidas intuitivamente como importantes, então estamos engajados na arte. Comum a ambas é a devoção 
amorosa àquilo que transcende as preocupações pessoais... (EINSTEIN apud ARAÚJO-JORGE,2004, p.36)

No artigo "The ArtScience Program for Realizing Human Potential", o artista, inventor e pesquisador Todd Siler (2011) afirma que a proposta da ArtScience, citada anteriormente, pode ser aplicada em diferentes processos de produção de conhecimento, sejam eles artísticos e/ou científicos, pois trata-se de um método inovador que permite pensar os processos de maneira criativa e produzir um pensamento crítico que leve à solução de problemas reais. As dificuldades concretas para a produção de conhecimento, seja ele artístico ou científico, fazem parte do cotidiano e é preciso buscar ferramentas que colaborem entre si para promover as mudanças necessárias para o desenvolvimento das pesquisas. O uso das artes pode ser bastante útil para compreender os modelos científicos e vice-versa, mas não se trata de utilizar as ferramentas e métodos artísticos para solucionar problemas científicos, pelo contrário, trata-se de questionar, problematizar e compreender os processos artísticos para melhor compreender e solucionar os processos científicos, pois ambos são ferramentas para compreensão e intervenção no mundo. Os modelos de compreensão é que devem ser compreendidos e, a partir deles, podem ser criados novos modelos, fora dos esquemas e modelos tradicionais, permitindo ao aluno criar novas ferramentas de compreensão e produzir novos meios simbólicos e abstratos para conduzir sua ação prática. Pois este processo serve a usos comuns, globais, pois ambos trabalham com a linguagem universal da criatividade e da invenção de novos arranjos seja na arte ou na ciência. O modelo proposto pelo Manifesto ArtScience propõe então ampliar a percepção de problemas reais, reformular as bases de sua definição, produzir novos modelos de compreensão que levem à busca por soluções. Conectando a definição do problema com a sua dimensão prática, criando métodos e hipóteses que ajudem a compreender o problema em novas bases, criando outras hipóteses que permitam experimentar diferentes modos de compreensão da realidade objetiva, analisando e inventando novas possibilidades de aplicação e intervenção no mundo real. Para Siler (2011), uma ilustração desse modelo poderia ser pensada como apresentado como: 


\section{O Método Cienciarte O Método científico}

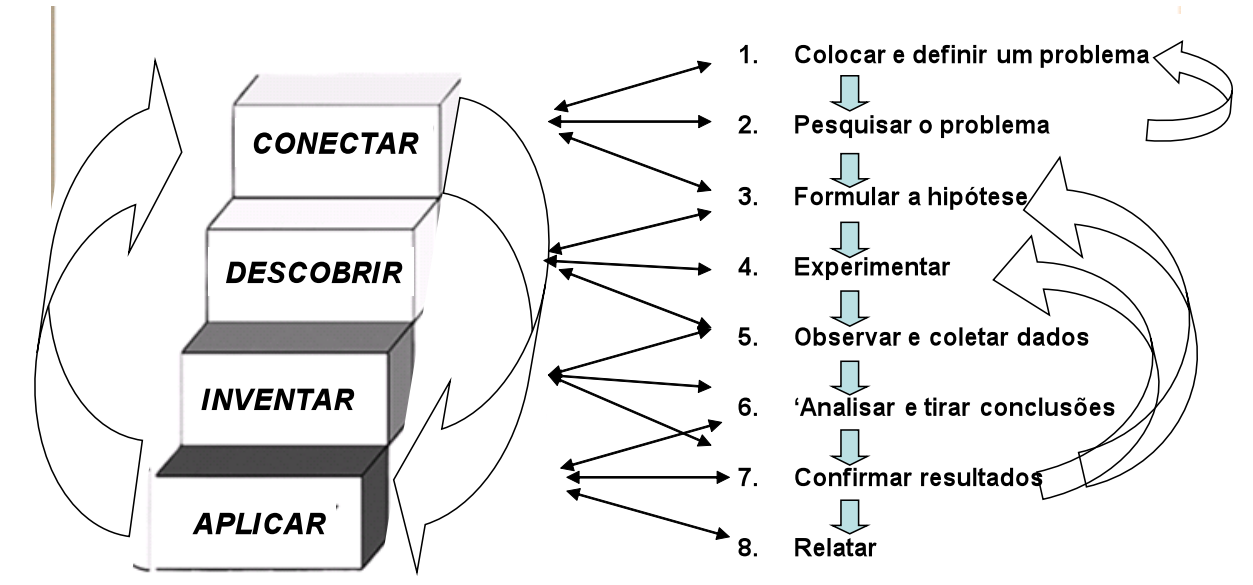

Figura 1. Metaformação do método científico em método cienciarte.(SILER, 2011, p. 420, figura traduzida)

Essa proposta de ressignificação dos problemas e a busca de soluções a partir do entendimento de modelos já existentes ou criados a partir da interação com a realidade não se constitui em novidade. Freire (1987), por exemplo, afirma que não há saber mais ou saber menos: há saberes diferentes. No entanto, essas diferenças encontram algo em comum na arte e na ciência: a criatividade e a cognição, o constante aprendizado. Apesar de desconhecermos o que leva ao processo de criação, certamente concordamos em que todos os indivíduos podem ser criativos, e que é possível reconhecer algo criativo como algo diferente, algo que se identifica no resultado final ou na abordagem que levou ao resultado. Root-Bernstein e Root-Bernstein (2001) acham que não é meramente a sorte ou coincidência que atuam no sucesso de cientistas que também desenvolvem potencialidades artísticas, e que existe algo mais profundo, e não imediatamente óbvio, que liga, por exemplo, a música e a cardiologia. Ele defende explicitamente que a música - ou qualquer arte bem praticada- é um excelente treinamento para um futuro doutor, porque aguça as muitas habilidades de que ele precisará como médico. Em alguns casos, pode inclusive lhe fornecer as ferramentas. Esse autor mostra que a história da medicina é rica em exemplos dessa interação, tais como: Leopold J. Auenbrugger (1722-1809), um austríaco que era médico e músico e inventou a percussão do tórax, método clássico usado nos exames clínicos, baseado na simples analogia entre a caixa torácica e um tambor; ou ainda René Laennec (1781-1826), médico, artista, flautista, poeta, compositor de ópera e inventor do estetoscópio, como uma simples extensão dos tubos de 
flautas. A interação entre ciência e arte se expressa também nas artes plásticas que são consideradas excelente treinamento para os cientistas. Diversos cientistas fizeram com dificuldade a escolha profissional pela ciência e não pela arte. Assim aconteceram com Békésy, com Max Planck e com Wilhelm Ostwald, três cientistas que receberam o prêmio Nobel. Cientistas e artistas lidam com as inquietações da descoberta, as regras, com as heranças culturais e transformações do conhecimento ao longo dos anos. Ligada a todas as áreas de conhecimento e facilitadora para o trabalho interdisciplinar, a arte pode proporcionar a junção, a integração de transversalidade em todos os espaços de educação.

\title{
4 CONSIDERAÇÕES FINAIS
}

Para que a ciência aconteça, muitas vezes o acaso e a criatividade fazem com que os métodos tradicionais sejam superados. Para Boaventura de Souza Santos, o método científico assenta na redução da complexidade (SANTOS, 2004). Ainda segundo Santos,

\begin{abstract}
A ciência moderna não é a única explicação possível da realidade e não há sequer qualquer razão científica para considerá-la melhor que as explicações alternativas da metafísica, da astrologia, da religião, da arte ou da poesia. A razão porque privilegiamos hoje uma forma de conhecimento que assente na previsão e no conteúdo dos fenômenos nada tem de científico. É um juízo de valor. (SANTOS, 2004, p.83).
\end{abstract}

Segundo Marilena Chauí (2004), a ciência contemporânea baseia-se, entre outros, na criação de uma linguagem específica e própria, distante da linguagem cotidiana e da linguagem literária e que procura afastar os dados qualitativos e perceptivo-emotivos dos objetos ou dos fenômenos, para guardar ou construir apenas seus aspectos quantitativos e relacionais. Assim, "o modelo tradicional de ciência não consegue analisar totalmente as relações possíveis entre a arte e a ciência”. É preciso então buscar outros métodos que nos permitam olhar para o tema do nosso trabalho de modo mais livre. Cienciarte é a nossa proposta, e tem sido ativamente experimentado pelo nosso grupo nos mais diferentes tipos de cursos. Até agora, com sucesso. 


\section{REFERÊNCIAS}

ARAÚJO-JORGE, T.C. (org.) Ciência e Arte: encontros e sintonias. Rio de Janeiro: Editora SENAC, 2004.

ARAÚJO-JORGE, T.C., BARBOSA, J.V., LEMOS, E.S. A implantação da Pós-graduação em Ensino em Biociências e Saúde (PG-EBS) na Fundação Oswaldo Cruz: experiências, lições e desafios. Revista Brasileira de Pós-Graduação 2006; 3(5): 87-106.

BAYER, R. História da Estética. Lisboa: Editorial Estampa, 1995.

BURKE, P. Uma história social do conhecimento: de Gutenberg a Diderot. Rio de Janeiro: Zahar, 2003.

COSTA, C. Questões de Arte: o belo, a percepção estética e o fazer artístico. Rio de Janeiro: Moderna, 2004.

DE MEIS, L. O Conflito entre a Ciência e a Arte - A dicotomia; conceitos e preconceitos entre os estudantes; criatividade artística versus criatividade científica. In O Conflito HumanoTecnológico. Ciência e Educação; Rio de Janeiro: Grafitex, 1998.

DELEUZE, G. O que é a Filosofia. Rio de Janeiro: Editora 34, 1992.

FERREIRA, F.R. Ciência e arte: investigações sobre identidades, diferenças e diálogos. Revista Educação e Pesquisa 2010; 36 (01): 261-280.

FREIRE, P. Pedagogia do oprimido. 17ª ed. Rio de Janeiro: Paz e Terra, 1987.

JIMENEZ, M. O que é Estética. São Leopoldo, RS: UNISINOS, 1999.

KLUCHNIKOV, B., "Education and Learning for the 21st Century: A Priority Agenda" in "Information Paper for the International Commission on Education for the 21 st Century," UNESCO, 5th version, p. 8, June, 1992.

MORIN, E. Os sete saberes necessários à educação do futuro. (SILVA, C.E.F., SAWAYA, J. trad.) 2 ed. São Paulo: Cortez, Brasília, DF: UNESCO, 2000.

PESSOA, F. Poesia Completa de Álvaro de Campos. São Paulo: Companhia de Bolso, 2013.

RONAN, C.A. História Ilustrada da Ciência-Universidade de Cambridge. Rio de Janeiro: Zahar, 1987.

ROOT-BERNSTEIN, R., ROOT-BERNSTEIN, M. Centelhas de Gênios: Como pensam as pessoas mais criativas do mundo. São Paulo: Nobel, 2001.

, SILER, T., BROWN, A., SNELSON, K., "ArtScience: Integrative

Collaboration to Create a Sustainable Future" in LEONARDO, Vol. 44, No. 3, p 192, Cambridge: MIT Press, 2011.

ROSA, L. P. Tecnociências e Humanidades: novos paradigmas, velhas questões, v. I. São Paulo: Paz e Terra, 2005. 
RUSSEL, B. História do pensamento ocidental. Rio de Janeiro: Ediouro, 2003.

REIS, J.C.; GUERRA, A.; BRAGA, M. Ciência e arte: relações improváveis? História, Ciências, Saúde-Manguinhos, v. 13, p. 71-88, Rio de Janeiro: Editora Fiocruz, 2006.

SILER, T. "The ArtScience Program for Realizing Human Potential” in LEONARDO, Vol. 44, No. 5, pp. 417-424, Cambridge: MIT Press, 2011.

SNOW, C.P. As duas culturas e uma segunda leitura. São Paulo: Edusp, 1995.

Recebido em 29 de maio de 2017 Aprovado em 28 de setembro de 2017 